\title{
The Selah pilot study of spiritual, mindfulness, and stress inoculation practices on stress-related outcomes: A non-randomized participant preference control pilot study
}

\section{Rae Jean Proeschold-Bell ( $\nabla$ rae.jean@duke.edu )}

Duke University https://orcid.org/0000-0003-2008-3053

David E. Eagle

Duke University

Logan C. Tice

Duke University

Jia Yao

Duke University

Joshua A. Rash

Memorial University of Newfoundland

Jessica Y. Choi

Duke University

\section{Beth Stringfield}

Duke University

\section{Sofia M. Labrecque}

Duke University

\section{Research}

Keywords: life stress, job stress, work related stress, mindfulness-based stress reduction, spiritual

Posted Date: November 11th, 2021

DOI: https://doi.org/10.21203/rs.3.rs-1056451/v1

License: (a) This work is licensed under a Creative Commons Attribution 4.0 International License. Read Full License 


\section{Abstract \\ Background}

The job-demand-control-support model indicates that clergy are at high risk for chronic stress and adverse health outcomes.

\section{Methods}

A non-randomized participant preference design with a control group was used to evaluate the feasibility, acceptability, and range of outcome effect sizes for four potentially stress-reducing interventions: stress inoculation training, mindfulness-based stress reduction (MBSR), the Daily Examen, and Centering Prayer. All United Methodist clergy in North Carolina were eligible and recruited via email to attend their preferred intervention: in-person workshops of one (Daily Examen, Centering Prayer) or two days (stress inoculation training) at retreat centers, or eight weekly online 90-minute sessions (MBSR). Surveys at 0, 3, and 12 weeks assessed symptoms of stress, anxiety, and perceived stress reactivity. Heart rate variability was assessed at baseline and 12 weeks using data from $24 \mathrm{~h}$ ambulatory heart rate monitoring. A patched-up control group was recruited after recruitment commenced. A subset of participants completed in-depth interviews and reported skill practice using daily text messages. Standardized mean differences with $95 \%$ and $75 \%$ confidence intervals were calculated for each intervention relative to control to determine the range of effect sizes likely to be observed in a definitive trial.

\section{Results}

78 clergy participated in an intervention and 7 provided data as a control group. The daily percentage of participants engaging in stress management practices ranged from 47\% (MBSR) to 69\% (Examen). Every participant interviewed $(n=23)$ reported that learning content was acceptable and they would recommend their intervention to others. Small-to-large effect sizes on measures of stress and anxiety were observed for Daily Examen, stress inoculation, and MBSR relative to control. Little evidence for change in HRV was observed between intervention and control, with the most favorable effects observed for MBSR. Results were mixed for Centering Prayer.

\section{Conclusions}

All four interventions were feasible and acceptable, with the best trends in outcomes for MBSR, although other interventions were promising. Participants welcomed daily text messages reminding them to engage in practice and wore ambulatory heart rate monitoring devices without incident. Three-week survey data did not contribute to study findings. Trial registration: ClinicalTrials.gov trial registration number: NCT04625777, November 12, 2020 (retrospectively registered). 


\section{Key Messages Regarding Feasibility}

1) It was unknown whether and how much Methodist clergy would participate in each of the four interventions, including a gold standard stress reduction program of mindfulness-based stress reduction and two spiritual practices, one of which (the Daily Examen) derives from the Catholic tradition. Clergy's willingness to report their practice engagement in a daily text message and to wear heart rate monitors was also unknown.

2) The study findings indicate that all four interventions were acceptable and feasible to Methodist clergy, with Centering Prayer being the least popular and Stress Proofing, which was the only one to include an overnight stay, being the most popular. Participants indicated benefit in reporting their practice daily via text and engaged in follow-up sessions.

3) Finding implications for the main study include offering short follow-up sessions via web platform at two and four weeks post-intervention, offering an overnight stay, decreasing didactic content for Stress Proofing, removing the three-week survey time point, and retaining heart rate variability and daily text message data collection.

\section{Background}

Experiencing stress at levels detrimental to health is common, yet how to manage stress and its concordant symptoms is still illusive for many people. We sought to assess the feasibility, acceptability, and range of potential effects of four sets of potentially helpful practices, including two spiritual practices. We chose a mix of spiritual and non-spiritual practices for our study population of an occupational group of clergy, who have been shown to have above-average rates of diseases including hypertension, diabetes, arthritis, angina, and asthma (1).

Physiological stress responses occur when one experiences a stressor and perceives that the demands exceed one's personal and social resources (2). Brief bouts of stress can be protective, but chronic stress can take a toll through allostatic overload (3). Chronic stress has been associated with a vast array of diseases including metabolic syndrome, including weight gain, dyslipidemia, type 2 diabetes, and hypertension (4), to a moderately elevated (i.e., 10-40\%) risk of heart attack and stroke (5). It is particularly important to reduce allostatic overload among people with chronic diseases to prevent further deterioration.

Chronic stress is common. Thirty-five percent of United States (US) adults indicated being extremely stressed over the last month, and almost one-third reported attending a doctor's appointment for stressrelated complaints (6). Clergy report high levels of stress; a literature review of clergy mental health articles from 1975-2000 found high levels of occupational stress across denominations and attributed the stress to "extraordinary demands," criticism, congregational conflicts, and expectations of clergy family members (7). Clergy exhibit physical health indicators of chronic stress, including diabetes, hypertension, asthma, joint-related disease, cardiovascular disease, and obesity $(1,8,9)$. Further, studies 
indicate high rates of anxiety among clergy (e.g., 10,11,12) and above-average rates of depression compared to non-clergy $(10,12)$.

The job-demand-control-support (JDCS) model indicates that stressful jobs are characterized by high demand, low control, and low support (13). Requiring a broad skill set (14), clergy perform many demanding roles, including inspiring the congregation, providing one-on-one care for congregants, performing sacraments, educating congregants, overseeing educational programming, leading social justice activities, and attending to unexpected needs and conflict (15). The work week typically averages 50 hours or more with the expectation of being on call around-the-clock (16). Clergy direct a mainly volunteer workforce and, with the wide range of tasks conducted, often do not receive the support needed to match the tasks or the emotional challenges faced $(17,18)$.

The clergy profession is a prime example of having a calling with unbounded work hours. The ambiguity of which direction to take and which needs to prioritize are stressors for clergy. Even though clergy report a strikingly high degree of satisfaction with work $(19,20)$, which can be deeply meaningful and thus lifeenriching (21), they also frequently report emotional exhaustion and a lack of personal accomplishment (22). Clergy are similar to other employees who are called to their work (e.g., medical providers, first responders, and social workers) and could benefit from stress management practices.

Researchers have developed numerous approaches to manage stress. The most prominent approaches include aspects of cognitive-behavioral therapy, mindfulness, and relaxation (23). Stress-reducing activities are viewed as skills that require regular practice $(24,25)$. As such, the most effective interventions are those that individuals are willing and motivated to practice (i.e., patient preferences are an important aspect of evidence-based practice; (26)). Pilot and feasibility study data can provide important information about occupational workers and their willingness to engage in stress management practices. For example, $83 \%$ of newly registered nurses in a pilot study were willing to engage in 4 hours of training on proactive, protective behaviors such as asking for help (27), and early elementary school teachers attended $87 \%$ of 27 hours of training in mindfulness-based stress reduction, but suggested shortening it and making more explicit links to their teaching (28).

Following best practices for developing behavioral treatments (29), we conducted Phase-ll preliminary testing of four potentially stress-reducing interventions to: 1) evaluate the feasibility and acceptability of the trial protocols; 2 ) inform intervention modifications; and 3) provide initial estimates of effect needed to design an adequately powered Phase III efficacy trial. The interventions included two spiritual practices: the Daily Examen and Centering Prayer. We also tested an intervention combining diaphragmatic breathing techniques with stress inoculation training. Finally, we included mindfulnessbased stress reduction (MBSR) as a gold standard stress-management intervention shown to provide changes in both self-reported (30) and biometric indicators of stress (31). The goal of this pilot intervention study was to determine interest in each of four interventions that we believed would be acceptable to clergy, collect data to inform modification of intervention content and delivery, and identify 
trends in outcomes to inform an adequately powered trial evaluating the most promising stress-reduction interventions.

\section{Methods}

\section{Study population}

All appointed clergy members in July 2018 of the North Carolina Annual Conference and the Western NC Annual Conference of the United Methodist Church (UMC) were eligible to participate and identified through conference documents. No stress or health status inclusion criteria were used. A total of 1,642 clergy were eligible to participate, and we sought 70-120 for this pilot study.

\section{Study design and recruitment}

We employed a non-randomized participant preference design with a control group. Recruitment involved an extensive communication campaign using a mailed paper invitation, email, UMC electronic newsletters, and in-person appeals at clergy meetings. Interested clergy were directed to a website where, after consenting online, clergy provided demographic information and chose an intervention workshop to attend (two date/location options were provided for each workshop; interventions occurred at small retreat centers). Clergy intervention preference included a combination of the intervention content, dates, and location.

After recruitment for the interventions commenced, additional participants were recruited to serve as a control group. Clergy who enrolled in an intervention workshop but were ultimately not able to attend due to schedule changes on their part were invited to stay in the study as a measurement-only control group. In addition, by email we invited a convenience sample of clergy who met study criteria to join the control group. Data were collected from controls from May through October of 2019. The Duke University Campus Review Board approved all procedures (protocol \#2019-0238) and participants gave free and informed consent.

\section{Interventions}

Mindfulness Based Stress Reduction (MBSR). We included an option to participate in MBSR as a gold standard for stress reduction $(32,33)$. MBSR uses secular meditation techniques to train attention to one's thoughts and body to encourage cognitive appraisal to stressors and reduce emotional reactivity (34). The MBSR curriculum of 8 weekly sessions were conducted via videoconference with a phone option by trained MBSR instructors, using the national model first developed by Jon Kabat-Zinn (32). It included exercises in awareness of breath, body scans, walking meditation, "choiceless" open awareness, Loving Kindness Meditation, and bringing awareness to the present moment. An optional, in-person Day of Mindfulness was included. Participants were encouraged to practice for 45-60 minutes/day the 
content covered in that week's class for the first 8 weeks, and for an additional 4 weeks, in formal practice of any of the exercises.

Stress Proofing. We included an intervention called Stress Proofing, which is a set of multiple stress reduction skills with aspects of stress inoculation training (35), curated, combined, and delivered by the founder of an organization called NCSystema. Two people from NCSystema designed and led a two-day, overnight workshop with 11 hours of content. Consistent with stress inoculation training, the workshop content began with education on how people respond to stress, followed by ways to become aware of when and how one responds to stress and how the effects of stress can linger in the body $(2,35)$. The training then diverged from traditional stress inoculation training and focused on physical activities to undo the stress response. These activities included walking with diaphragmatic breathing, triangle and rectangle breathing, tension control, stretching, and massaging the muscles around the ribcage near the vagus nerve where tension is often held. The workshop included a discussion on stress inoculation training, encouraging participants during periods of less stress to allow themselves a degree of physical discomfort to learn to tolerate discomfort in preparation for future stressors (36). As an example, participants laid down on itchy, wet grass for five minutes. The workshop content also included a variety of lifestyle recommendations such as prioritizing nutrition and sleep and disengaging from technology for several hours before sleep. The daily practice plan emphasized stress awareness and diaphragmatic breathing, with encouragement to try the lifestyle adjustments for a few days at a time.

We recommended that participants practice the skills learned for 10-25 minutes per day for three months. We gave participants a book created for the study that covered the information learned in the workshop and provided a daily practice plan for each of 30 days, beginning immediately after the workshop. Three weeks after the workshop, one instructor offered a one-hour class session via videoconference.

Daily Examen (Examen). The Examen is a Jesuit prayer practice (37) that we chose because an earlier qualitative study of ours found that clergy with high levels of positive mental health and low levels of burnout handle criticisms through asking if and how they relate to their current mission, a practice which they conceptualized as working in alignment with God (38). If the criticism did not relate to their current mission, clergy could more easily move on from it. The Examen seemed a promising brief intervention to help clergy work in alignment with God through its five steps: 1) Become aware of God's presence; 2) Give thanks to God for everything in your life; 3) Review the events of the day guided by the Holy Spirit; 4) Look at what went well or wrong in the past day; if at fault, ask God for forgiveness; and 5) Look toward to tomorrow - what one thing should you do? Listen to what God is telling you.

Two experts on the Examen designed and led a one-day workshop with 5 hours of content, which included 2, 15-minute Examen practice sessions. The lead instructor also offered 2, 1-hour follow-up sessions with cohorts of up to 4 participants on a videoconference approximately 2 and 4 weeks after the workshop. We recommended that participants practice the Examen, which typically takes 10-15 minutes, every day for 3 months. 
Centering Prayer. We chose Centering Prayer because it is a meditative practice, which generally have been shown effective at reducing stress (39), and we thought the spiritual aspects of Centering Prayer might make it acceptable to clergy. Few studies on Centering Prayer exist, but one reported promising reductions in perceived stress and anxiety symptoms (40), and another found that participants became more aware of God's presence in their lives (41). An expert in Centering Prayer designed and led a 1-day workshop with 3.5 hours of content, which included 2, 20-minute Centering Prayer practice sessions. Participants were taught to set a signal, such as a chime alarm before beginning practice and then to sit quietly and empty their mind of thoughts, framed as time to "rest in the arms of God." If intrusive thoughts arose, they were instructed to return to their chosen word (e.g., "peace"). We also offered a single, 1-hour follow-up class videoconference session with the instructor 3 weeks after the workshop. We recommended that participants practice Centering Prayer for 20 minutes per day for 3 months.

\section{Measures and apparatus}

Our measures were designed to learn about feasibility, acceptability, preference, and suggestions for improving the interventions. In addition, we sought to evaluate a range of potential intervention effects on stress and anxiety symptoms and heart rate variability (HRV). Intervention participants were asked to complete online surveys at baseline (Time 1; usually immediately pre-workshop but possibly up to 6 days later), 3 weeks (Time 2), and 12 weeks (Time 3). They were also asked to provide heart rate variability (HRV) data at Time 1 (immediately post-workshop) and Time 3. Control participants were asked to complete surveys and HRV data at only two time points, 6-8 weeks apart, due to their late inclusion and short study timeline. We refer to these as Time 1 and Time 3 , although note that the control participants' Time 3 is sooner than that of the intervention participants'. Intervention participants were not compensated for their baseline survey and received \$2 25 for each additional survey, as well as \$25 per HRV assessment. Control participants were compensated \$25 each time they completed a survey and HRV assessment.

Each intervention was received by two cohorts. As a measure of intervention uptake, all participants were sent a daily text message for 12 weeks asking for the number of minutes practiced the prior day. Improvements in the text messaging system enabled the use of data from participants in the second cohort only.

\section{Survey measures}

The Calgary-Symptoms of Stress Inventory (C-SOSI) is a 56-item, 8-subscale measure of the frequency of self-reported stress symptoms over the past week (42). We included the subscales of anger (8 items; e.g., "easily annoyed and irritated"), muscle tension (8 items; e.g., "excessive tension, stiffness, soreness or cramping in the muscles in your shoulders"), cardiopulmonary arousal (6 items; e.g., "'Rapid breathing"; "Irregular heartbeats" while not exercising), neurological/gastroenterological (10 items; e.g., "nausea"), and cognitive disorganization (9 items; e.g., "how often does it seem your thinking gets mixed-up when you have to do things quickly?"). We did not include the subscale of depression because this study did 
not target depression. We did not include the subscales of sympathetic arousal and upper respiratory symptoms due to not finding change over time in these subscales in previous studies with this population. Validation studies have shown convergent validity with specific subscales and overall divergent validity with anxiety (42). Response options for the 41 items we included were on a scale from $0-4$; higher mean scores indicate worse symptoms.

The Perceived Stress Reactivity Scale (PSRS) is a 23-item measure of stress-reactivity from work overload, social conflicts, failure, and social evaluation, and prolonged reactivity (i.e., difficulty relaxing after a high workload day) (43). Based on cognitive interviews that we conducted with 33 clergy, we changed the PSRS response options from having only three options to four to promote response variability. We also edited some response options and some item stem wording (e.g., we changed the word "argue" to "disagree," because clergy indicated "argue" conveys anger and that they would not endorse it). Further, we created two additional items of our own, for a total of 25 items. These new items included changing "When I have conflicts with others" to two items: "conflicts with congregants or colleagues" and "conflicts with friends or family members." We also changed "When I do not attain a goal" to two items: "a work-related goal" and "a personal goal." In addition, we allowed participants to indicate "not applicable" to each item, because during the cognitive interviews, many clergy said that the situation in various items did not pertain to them. Response options were on a scale from $0-3$, and we scored items such that higher scores indicate more difficulty in reacting to stress.

To measure anxiety, we used the anxiety portion of the Hospital Anxiety and Depression Scale-Anxiety (HADS-A; 44). An example item is: "Over the past two weeks, how often have you been bothered by any of the following problems? I feel restless as if I have to be on the move." The seven items have response options on a scale of $0-4$, for a scale range of $0-28$. We considered scores of 8 and above to indicate probable anxiety (45).

For the purposes of describing the sample, the survey included demographic items for gender, age, race, Hispanic/Latino ethnicity, and education. We included financial stress ("How stressful is your current financial situation for you? Not at all, slightly, moderately, very, and extremely stressful"), marital status, having children of any age living at home or not (yes/no), and an indicator of rural/urban work location. In the adjusted models, we control for two variables which may relate to stress: gender and years of experience in ministry ("How many years have you been in ministry full or part-time for which you were paid a salary?"). In addition, we included the Clergy Occupational Distress Index to describe stressors at Time 1, using a time frame of the past 4 weeks. This measure has 5 items, including "how often have you experienced stress because of the challenges you have in this organization/congregation" and "how often have the people in your congregation made too many demands on you" (46).

\section{Heart rate variability measurement}

Heart rate was measured using continuous electrocardiographic (ECG) recording sampled at a rate of $1,000 \mathrm{~Hz}$. Participants were fitted with an eMotion Faros 180 ambulatory heart rate recording device 
(Bittium) connected by electrode leads to two pre-gelled (Ag/AgCl) disposable Ambu BlueSensor wet-gel ECG electrodes attached beneath the right clavicle and left ribcage. The ambulatory recording device was worn for 24 hours immediately following the intervention workshop and at 12-weeks post-workshop (or, for control participants, at 0 weeks and 6-8 weeks), during which time participants proceeded with their usual daily routines and sleep activities.

Using the Mindware HRV Analysis 3.0.3 software (Gahanna, $\mathrm{OH}$ ), the 24-hour ECG data were partitioned into 300-second segments that were linearly detrended, and subject to a Hamming window. Each segment was scanned for artifacts according to accepted standards (47). Segments with artifacts in excess of $10 \%$ were excluded. Interbeat intervals (IBIs) were calculated as the time between successive Rpeaks. The root mean square of successive differences (RMSSD) was used as a time domain-based index corresponding to parasympathetic regulation of the heart. The RMSSD is less affected by breathing and is therefore a suitable outcome measure in ambulatory studies (48).

Following recommendations for the detection of circadian rhythmicity (49), 5-minute segments across 24 hours of recording were subject to a cosinor analysis using the Cosinor package for $\mathrm{R}(50)$. Two individual-level cosine function parameters were estimated by linear models with ordinary least square estimations to quantify the circadian variability parameters: 1) midline estimating statistic of rhythm (MESOR) defined as the rhythm adjusted 24-hour mean, and 2) amplitude, defined as the distance between MESOR and the maximum of the cosine curve (i.e. half the extent of rhythmic change in a cycle). We assumed periods of 24 hours.

\section{In-depth interviews}

In-depth interviews with questions on acceptability and feasibility were conducted with a subset of participants. We selected some participants with high uptake and some with low uptake of the practices based on text message data. Interviews were conducted over the phone for 30-60 minutes using a semistructured design. One team member conducted content analysis (51). Interviewees were not additionally compensated for this interview.

\section{Statistical analysis}

We reported summary statistics of participants' demographic and occupational characteristics at Time 1, namely means and standard deviations for the continuous variables (age and experience in ministry); counts and percentages for the remaining variables). We examined baseline differences of the outcome variables with an ANOVA test across the 5 arms. For all outcome variables, we compared the means between the intervention participants and the control participants by Student's t test, and the percentages by $\chi^{2}$ test. We reported the means and standard deviations of continuous variables at Time 1 , Time 2 , and Time 3 .

Standardized mean differences (i.e., Cohen's $d$ ) and associated $95 \%$ and $75 \%$ Cls were calculated to explore the range of effect sizes likely to be observed on surveys and HRV within an adequately powered trial. Effect sizes were calculated as the mean difference from Time 1 to Time 3 (Time 2 for the control 
arm) with the pooled standard deviation being the denominator. Effect sizes were calculated within each treatment arm over time and comparing each intervention relative to the control group. Survey statistical analyses were conducted using Stata version 16.1 (52). Standard mean differences and confidence intervals were visualized using Microsoft Excel.

\section{Results}

\section{Participation}

Recruitment occurred September-December 2018. The interventions occurred January-May 2019; data from intervention participants were collected from January-September 2019. A total of 78 participants enrolled with the intent to participate in one of the interventions. The intervention arm that was preferred by most participants was Stress Proofing ( $n=29,41 \%)$, followed by the Examen $(n=17,24 \%)$, MBSR $(n=13$, $18 \%)$, and Centering Prayer $(n=12,17 \%)$. A total of 7 participants did not receive an intervention due to scheduling conflicts and provided data as a control arm.

Demographic characteristics are reported in Table 1. The mean score on a measure of clergy stressors, the Clergy Occupational Distress Index, was 6.6. To compare, other studies have reported means of 11.0 for a nationally representative sample of clergy $(n=879)$ and 11.8 for clergy of Protestant denominations $(n=843),(46)$. 
Table 1

Participant characteristics by intervention arm

\begin{tabular}{|c|c|c|c|c|c|c|}
\hline & $\begin{array}{l}\text { Combined } \\
(\mathrm{n}=78) \\
\mathrm{n}(\%) \text { or } \mathrm{M} \\
(\mathrm{SD})\end{array}$ & $\begin{array}{l}\text { MBSR } \\
(n=13) \\
n(\%) \text { or } \\
M(S D)\end{array}$ & $\begin{array}{l}\text { Stress } \\
\text { Proofing } \\
(n=29) \\
n(\%) \text { or } \\
M(S D)\end{array}$ & $\begin{array}{l}\text { Daily } \\
\text { Examen } \\
(n=17) \\
n(\%) \text { or } \\
M(S D)\end{array}$ & $\begin{array}{l}\text { Centering } \\
\text { Prayer } \\
(n=12) \\
n(\%) \text { or } \\
M(S D)\end{array}$ & $\begin{array}{l}\text { Control } \\
\text { arm } \\
(n=7) \\
n \text { (\%) or } \\
M(S D)\end{array}$ \\
\hline \multicolumn{7}{|l|}{ Gender } \\
\hline Male & $43(56.6)$ & $7(58.3)$ & $\begin{array}{l}12 \\
(41.4)\end{array}$ & $\begin{array}{l}13 \\
(76.5)\end{array}$ & $8(66.7)$ & $3(50.0)$ \\
\hline Female & $33(43.4)$ & $5(41.7)$ & $\begin{array}{l}17 \\
(58.6)\end{array}$ & $4(23.5)$ & $4(33.3)$ & $3(50.0)$ \\
\hline Age & $\begin{array}{l}51.8(\mathrm{SD} \\
10.5)\end{array}$ & $\begin{array}{l}52.3 \\
(S D \\
10.0)\end{array}$ & $\begin{array}{l}53.1 \\
(S D 9.3)\end{array}$ & $\begin{array}{l}50.5 \\
(\mathrm{SD} \\
12.1)\end{array}$ & $\begin{array}{l}52.2(\mathrm{SD} \\
11.2)\end{array}$ & $\begin{array}{l}46.3 \\
(S D \\
12.6)\end{array}$ \\
\hline $\begin{array}{l}\text { Experience in vocational } \\
\text { ministry (in years) }\end{array}$ & $\begin{array}{l}15.9(\mathrm{SD} \\
9.6)\end{array}$ & $\begin{array}{l}18.6 \\
(S D 8.0)\end{array}$ & $\begin{array}{l}16.5 \\
(S D \\
10.2)\end{array}$ & $\begin{array}{l}16.4 \\
(S D 9.1)\end{array}$ & $\begin{array}{l}12.8(\mathrm{SD} \\
10.6)\end{array}$ & $\begin{array}{l}12(\mathrm{SD} \\
8.9)\end{array}$ \\
\hline \multicolumn{7}{|l|}{ Race } \\
\hline White, single racial & $68(89.5)$ & $\begin{array}{l}11 \\
(91.7)\end{array}$ & $\begin{array}{l}27 \\
(93.1)\end{array}$ & $\begin{array}{l}17 \\
(100)\end{array}$ & $8(66.7)$ & $5(83.3)$ \\
\hline $\begin{array}{l}\text { Black/African American, } \\
\text { single racial }\end{array}$ & $1(1.3)$ & $1(8.3)$ & $0(0)$ & $0(0)$ & $0(0)$ & $0(0)$ \\
\hline $\begin{array}{l}\text { Asian American/Pacific } \\
\text { Islander, single racial }\end{array}$ & $2(2.6)$ & $0(0)$ & $0(0)$ & $0(0)$ & $2(16.7)$ & $0(0)$ \\
\hline Bi-/multi-racial & $5(6.6)$ & $0(0)$ & $2(6.9)$ & $0(0)$ & $2(16.7)$ & $1(16.7)$ \\
\hline \multicolumn{7}{|l|}{ Education } \\
\hline Bachelor's degree or less & $12(15.8)$ & $1(8.3)$ & $4(13.8)$ & $2(11.8)$ & $3(25.0)$ & $2(33.3)$ \\
\hline Master's degree & $57(75.0)$ & $\begin{array}{l}11 \\
(91.7)\end{array}$ & $\begin{array}{l}25 \\
(86.2)\end{array}$ & $\begin{array}{l}11 \\
(64.7)\end{array}$ & $8(66.7)$ & $2(33.3)$ \\
\hline Doctoral degree & $7(9.2)$ & $0(0)$ & $0(0)$ & $4(23.5)$ & $1(8.3)$ & $2(33.3)$ \\
\hline \multicolumn{7}{|l|}{ Financial stress } \\
\hline Extremely stressful & $2(2.6)$ & $0(0)$ & $2(6.9)$ & $0(0)$ & $0(0)$ & $0(0)$ \\
\hline Very stressful & $10(13.2)$ & $2(16.7)$ & $2(6.9)$ & $4(23.5)$ & $2(16.7)$ & $0(0)$ \\
\hline Moderately stressful & $25(32.9)$ & $5(41.7)$ & $\begin{array}{l}10 \\
(34.5)\end{array}$ & $4(23.5)$ & $4(33.3)$ & $2(33.3)$ \\
\hline
\end{tabular}




\begin{tabular}{|c|c|c|c|c|c|c|}
\hline & $\begin{array}{l}\text { Combined } \\
(\mathrm{n}=78) \\
\mathrm{n}(\%) \text { or } \mathrm{M} \\
(\mathrm{SD})\end{array}$ & $\begin{array}{l}\text { MBSR } \\
(n=13) \\
n(\%) \text { or } \\
M(S D)\end{array}$ & $\begin{array}{l}\text { Stress } \\
\text { Proofing } \\
(n=29) \\
n(\%) \text { or } \\
M(\text { (SD) }\end{array}$ & $\begin{array}{l}\text { Daily } \\
\text { Examen } \\
(n=17) \\
n(\%) \text { or } \\
M(\text { (SD) }\end{array}$ & $\begin{array}{l}\text { Centering } \\
\text { Prayer } \\
(n=12) \\
n(\%) \text { or } \\
M(S D)\end{array}$ & $\begin{array}{l}\text { Control } \\
\text { arm } \\
(n=7) \\
n(\%) \text { or } \\
M(S D)\end{array}$ \\
\hline Slightly stressful & $30(39.5)$ & $5(41.7)$ & $\begin{array}{l}11 \\
(37.9)\end{array}$ & $8(47.1)$ & $4(33.3)$ & $3(33.3)$ \\
\hline Not at all stressful & $9(11.8)$ & $0(0)$ & $4(13.8)$ & $1(5.9)$ & $2(16.7)$ & $2(33.3)$ \\
\hline \multicolumn{7}{|l|}{ Marital status } \\
\hline Never married or widowed & $6(7.9)$ & $1(8.3)$ & $1(3.5)$ & $2(11.8)$ & $2(16.7)$ & $0(0)$ \\
\hline Married & $62(81.6)$ & $\begin{array}{l}10 \\
(83.3)\end{array}$ & $\begin{array}{l}23 \\
(79.3)\end{array}$ & $\begin{array}{l}14 \\
(82.4)\end{array}$ & $9(75.0)$ & $6(100)$ \\
\hline Divorced or separated & $8(10.5)$ & $1(8.3)$ & $5(17.2)$ & $1(5.9)$ & $1(8.3)$ & $0(0)$ \\
\hline Children at home (Yes) & $37(48.7)$ & $8(66.7)$ & $\begin{array}{l}11 \\
(37.9)\end{array}$ & $7(41.2)$ & $7(58.3)$ & $4(66.7)$ \\
\hline \multicolumn{7}{|l|}{ Rural/urban status } \\
\hline Rural or open country & $22(29.3)$ & $4(33.3)$ & $5(17.9)$ & $5(29.4)$ & $4(33.3)$ & $4(66.7)$ \\
\hline $\begin{array}{l}\text { Town or village of less than } \\
10,000 \text { people }\end{array}$ & $21(28.0)$ & $3(25.0)$ & $8(28.6)$ & $4(23.5)$ & $6(50.0)$ & $0(0)$ \\
\hline $\begin{array}{l}\text { In or around city of } 10,000- \\
249,000 \text { people }\end{array}$ & $23(30.7)$ & $3(25.0)$ & $\begin{array}{l}10 \\
(35.7)\end{array}$ & $7(41.2)$ & $2(16.7)$ & $1(16.7)$ \\
\hline $\begin{array}{l}\text { In or around city of } 250,000 \\
\text { or more people }\end{array}$ & $9(12.0)$ & $2(16.7)$ & $5(17.9)$ & $1(5.9)$ & $0(0)$ & $1(16.7)$ \\
\hline $\begin{array}{l}\text { Clergy Occupational } \\
\text { Distress Index (CODI) }\end{array}$ & $\begin{array}{l}6.6(S D \\
3.3)\end{array}$ & $\begin{array}{l}8.5(S D \\
3.6)\end{array}$ & $\begin{array}{l}6.2(S D \\
2.9)\end{array}$ & $\begin{array}{l}7.2(S D \\
3.5)\end{array}$ & $\begin{array}{l}5.1(\mathrm{SD} \\
2.1)\end{array}$ & $\begin{array}{l}6(\mathrm{SD} \\
4.5)\end{array}$ \\
\hline
\end{tabular}

Intervention uptake

Mean daily response rates to the text messages ranged from $73-92 \%$ for 12 weeks (see Table 2).

Participation in all four interventions was high. The Daily Examen was the most frequently practiced with $60 \%$ of participants practicing on $80 \%$ of days, and when practiced, it was for an average of 11.3 minutes, which falls within the recommended time range. MBSR was the least practiced per day with $43 \%$ conducting formal MBSR practice on $50 \%$ of days, for an average of 22.6 minutes when practiced, although the recommended range was 45-60 minutes. On average, participants practiced within the recommended number of minutes for Stress Proofing and Centering Prayer. No harmful effects were reported. 
Table 2

Frequency and minutes of stress reduction practice by intervention

\begin{tabular}{|c|c|c|c|c|}
\hline & MBSR & $\begin{array}{l}\text { Daily } \\
\text { Examen }\end{array}$ & $\begin{array}{l}\text { Stress } \\
\text { Proofing }\end{array}$ & $\begin{array}{l}\text { Centering } \\
\text { Prayer }\end{array}$ \\
\hline Number of participants included in text data* & 7 & 10 & 14 & 4 \\
\hline Number of days with text data** & 588 & 840 & 1,176 & 336 \\
\hline $\begin{array}{l}\text { Average percentage of participants providing text } \\
\text { data per day }\end{array}$ & $72.6 \%$ & $92.1 \%$ & $79.3 \%$ & $81.3 \%$ \\
\hline $\begin{array}{l}\text { Average percentage of participants reporting doing } \\
\text { any practice per day }\end{array}$ & $47.3 \%$ & $68.9 \%$ & $60.4 \%$ & $56.5 \%$ \\
\hline $\begin{array}{l}\text { Percent of participants practicing at least } 80 \% \text { of the } \\
\text { days (reported practice) }\end{array}$ & $14.3 \%$ & $60 \%$ & $14.3 \%$ & $0 \%$ \\
\hline $\begin{array}{l}\text { Percent of participants practicing at least } 50 \% \text { of the } \\
\text { days (reported practice) }\end{array}$ & $42.9 \%$ & $80 \%$ & $71.4 \%$ & $75 \%$ \\
\hline $\begin{array}{l}\text { Percent of participants practicing less than } 33 \% \text { of } \\
\text { the days (reported practice) }\end{array}$ & $28.6 \%$ & $20 \%$ & $14.3 \%$ & $0 \%$ \\
\hline $\begin{array}{l}\text { Average number of minutes practiced per day (among } \\
\text { those who reported any practice) }\end{array}$ & $\begin{array}{l}24.5 \\
\text { minutes }\end{array}$ & $\begin{array}{l}11.3 \\
\text { minutes }\end{array}$ & $\begin{array}{l}15.8 \\
\text { minutes }\end{array}$ & $\begin{array}{l}20.3 \\
\text { minutes }\end{array}$ \\
\hline Number of recommended minutes of daily practice & $\begin{array}{l}45-60 \\
\text { minutes }\end{array}$ & $\begin{array}{l}10-15 \\
\text { minutes }\end{array}$ & $\begin{array}{l}10-25 \\
\text { minutes }\end{array}$ & $\begin{array}{l}20 \\
\text { minutes }\end{array}$ \\
\hline
\end{tabular}

In-depth interview results

We conducted in-depth interviews with 5-7 participants per arm. Themes are depicted in Table 3. Overall, all four interventions had acceptable learning content and practices. They were also all feasible in terms of the workshop attendance and practice uptake. $100 \%$ of participants in each arm reported that they would recommend the intervention to fellow clergy, despite how busy clergy are. Barriers to feasibility included being too busy to find time to practice when stress is highest, and, for the Daily Examen, finding it hard to practice when mentally fatigued. Barriers to acceptability were not having a spiritual emphasis in Stress Proofing and finding the quiet practices of Centering Prayer and the Daily Examen distracting to perform during a group workshop. 
Table 3

Feasibility and acceptability themes that emerged from the in-depth interviews by intervention arm

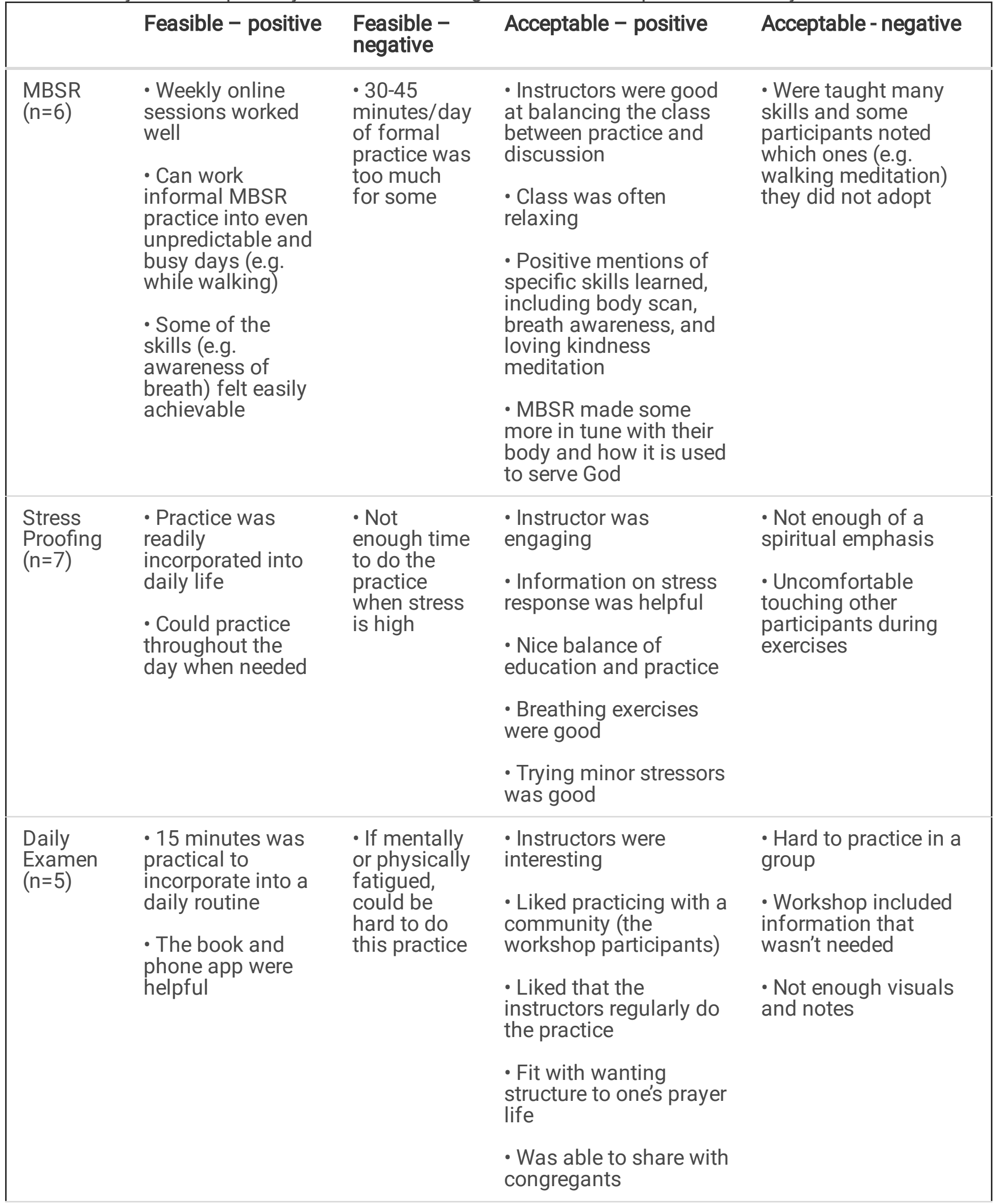




\begin{tabular}{|c|c|c|c|c|}
\hline & Feasible - positive & $\begin{array}{l}\text { Feasible - } \\
\text { negative }\end{array}$ & Acceptable - positive & Acceptable - negative \\
\hline $\begin{array}{l}\text { Centering } \\
\text { Prayer } \\
(n=5)\end{array}$ & $\begin{array}{l}\text { - Location and } \\
\text { date of the } \\
\text { workshop worked } \\
\text { well } \\
\text { - } 20 \text { minutes on } \\
\text { some days felt } \\
\text { possible }\end{array}$ & $\begin{array}{l}\text { - } 20 \text { minutes } \\
\text { every day } \\
\text { did not feel } \\
\text { possible }\end{array}$ & $\begin{array}{l}\text { - Instructor (who was a } \\
\text { pastor) was interesting, } \\
\text { helpful, relatable, and } \\
\text { compassionate } \\
\text { - The instructor bore } \\
\text { "powerful witness" to } \\
\text { the power of the } \\
\text { practice } \\
\text { - Appreciations for } \\
\text { contemplative spiritual } \\
\text { practices like this one } \\
\text { - Some felt "closer to } \\
\text { the Lord" and } \\
\text { experienced a "more } \\
\text { prayerful attitude" }\end{array}$ & $\begin{array}{l}\text { - Distracting to sit } \\
\text { quietly for so long in a } \\
\text { group }\end{array}$ \\
\hline
\end{tabular}


Table 4. Outcomes over time within each arm

Mean (SD)

Sample size at baseline

Time 1

Time 3 (Time 2 for Control)

C-SOSI stress symptoms, scale range 70

0-4

MBSR

12

1.02

$0.70(0.58)$

(0.46)

Stress Proofing

29

0.90

$0.55(0.36)$

$(0.50)$

Daily Examen

17

0.65

$(0.42)$

Centering Prayer

12

0.40

(0.27)

Control

7

0.56

(0.38)

$0.51(0.38)$

67

Stress reactivity, scale range 0-75

12

41.2

(10.6)

Stress Proofing

29

40.2

(12.2)

Daily Examen

15

38.7

(11.2)

Centering Prayer

11

32.2

(7.2)

$0.39(0.27)$

Control

7

36.8

(12.3)

$36.2(9.3)$

$0.59(0.38)$

HADS anxiety symptoms, scale range $0-21$

$\begin{array}{lcll}\text { MBSR } & 12 & \begin{array}{l}6.25 \\ (3.17)\end{array} & 4.21(3.20) \\ \text { Stress Proofing } & 29 & \begin{array}{l}4.72 \\ (3.30)\end{array} & 3.36(2.24) \\ \text { Daily Examen } & 17 & \begin{array}{l}4.65 \\ (3.06)\end{array} & 2.94(1.81) \\ \text { Centering Prayer } & 12 & 2.92 & 3.44(1.88) \\ & & (2.11) & \end{array}$




\begin{tabular}{|c|c|c|c|}
\hline Control & 7 & $\begin{array}{l}4.57 \\
(2.82)\end{array}$ & $3.71(2.75)$ \\
\hline MESOR RMSSD & 44 & & \\
\hline MBSR & 6 & $\begin{array}{l}34.8 \\
(16.7)\end{array}$ & $42.0(22.2)$ \\
\hline Stress Proofing & 14 & $\begin{array}{l}32.0 \\
(21.6)\end{array}$ & $26.6(16.4)$ \\
\hline Daily Examen & 11 & $\begin{array}{l}40.7 \\
(24.1)\end{array}$ & $42.9(16.8)$ \\
\hline Centering Prayer & 7 & $\begin{array}{l}35.9 \\
(28.6)\end{array}$ & $42.7(34.6)$ \\
\hline Control & 6 & $\begin{array}{l}39.5 \\
(19.4)\end{array}$ & $43.8(19.9)$ \\
\hline Amplitude RMSSD & 44 & & \\
\hline MBSR & 6 & $\begin{array}{l}14.7 \\
(13.5)\end{array}$ & $17.8(12.1)$ \\
\hline Stress Proofing & 14 & $\begin{array}{l}13.4 \\
(15.4)\end{array}$ & $8.2(7.5)$ \\
\hline Daily Examen & 11 & $\begin{array}{l}15.5 \\
(15.4)\end{array}$ & $15.9(11.8)$ \\
\hline Centering Prayer & 7 & $\begin{array}{l}14.9 \\
(20.9)\end{array}$ & $22.4(25.5)$ \\
\hline Control & 6 & $\begin{array}{l}22.3 \\
(16.6)\end{array}$ & $22.9(16.6)$ \\
\hline
\end{tabular}

Survey and HRV results

The survey response rates for intervention participants were $100 \%$ at Time $1,93 \%$ at Time 2 , and $93 \%$ at Time 3. The survey response rates for control participants were $100 \%$ at both Time 1 and Time 3 . Not all participants were asked to contribute HRV data; we used complete pairs of HRV data from 44 participants. At baseline, there was a significant difference between arms for the C-SOSI $(p=0.003)$, but not for Stress Reactivity or anxiety symptoms. Table 4 reports the means and standard deviations of the survey and HRV outcomes.

As shown in Table, 4, mean unadjusted survey scores changed in the expected direction from Time 1 to Time 3 for MBSR, Stress Proofing, and Daily Examen participants; results were mixed for Centering Prayer participants. Mean unadjusted HRV scores changed in the expected direction from Time 1 to Time 3 for MBSR and Centering Prayer participants, showed little change for Examen participants, and changed in 
the unexpected direction for Stress Proofing participants. Figure 1 depicts standardized mean differences and $75 \%$ and $95 \%$ confidence intervals when comparing within-group change from Time 1 to Time 3 . Participants in the MBSR, Stress Proofing, and Examen arms tended to report improvements in symptoms of stress, stress reactivity, and anxiety with medium-to-large effect sizes with $75 \% \mathrm{Cls}$ that generally exceeded 0 . The effect of Centering Prayer on survey-based measures of stress and anxiety were variable, and little to no evidence of change was observed among the control group. The effect of stress reducing interventions on HRV MESOR and amplitude were more variable, with only MBSR demonstrating a clear and consistent improvement over time.

Figure 2 depicts standardized mean differences, and $75 \%$ and $95 \%$ Cls comparing change among participants in each treatment arm from Time 1 to Time 3 relative to change among the control participants (survey $n=7 ; H R V n=6$ ) between Time 1 and Time 3 . Compared to control, participants reported improvements in symptoms of stress and stress reactivity from Time 1 to Time 3 with mediumto-large effect sizes with $75 \%$ Cls generally above 0 . Except Centering Prayer, stress reduction interventions tended to result in improvement in symptoms of anxiety with small effect sizes and Cls that crossed 0 . The effect of different interventions on HRV MESOR and amplitude were variable, with participants who completed Stress Proofing evidencing statistically significant reductions (i.e. worsening) from Time 1 to Time 3 relative to control. Further, relative to control, participation in MBSR tended to result in increases (i.e. improvement) in HRV MESOR, but little change in amplitude. The effect of Examen and Centering Prayer on HRV MESOR and amplitude were less conclusive.

\section{Discussion}

We performed a Phase-Il feasibility pilot study to determine which of four potential stress reduction interventions were acceptable, feasible, and potentially efficacious to proceed to a Phase-IIl efficacy trial. Each intervention was feasible and acceptable to Methodist clergy. Engagement was high across interventions with a majority of participants reporting engaging in intervention practice multiple days per week. Moreover, the range of effect sizes comparing interventions to control on symptoms of stress and stress reactivity encompassed thresholds for practical significance (mean difference > .41; 53). With the exception of Centering Prayer, the point estimate of effect for symptoms of stress and stress reactivity were at or below this threshold of practical significance which supports further examination in a Phase-III efficacy trial. The effect of interventions on HRV MESOR and amplitude were mixed with few interventions resulting in an appreciable change relative to control.

The primary reason to offer four different programming options to clergy was to discover which interventions they would find acceptable and feasible, and to identify barriers that might inform intervention redesign before proceeding to an adequately powered and resource-intensive trial. We allowed clergy to enroll in the intervention of their choosing, and we considered enrollment size to be an indicator of acceptability. Stress Proofing was the most popular, followed by the Daily Examen. Clergy may have been particularly attracted to Stress Proofing because it offered a two-night stay in a retreat center and few clergy had experience with its stress reduction practices. In contrast, all other interventions 
did not offer an overnight stay. Centering Prayer had the lowest enrollment, which may have been due to UMC clergy in North Carolina already having had opportunities to learn Centering Prayer through a nonprofit organization and due to the slightly less desirable and accessible locations offered. Interview comments on acceptability across the interventions were strongly positive. Participants noted that the two spiritual practices matched their desired prayer life and helped them feel closer to God. Interestingly, one participant also commented that MBSR connected them to their body and that this had a desirable outcome of helping them consider how their body is used to serve God. No one mentioned this connection for Stress Proofing, which also sought to put people in touch with their bodies. Instead, one participant who completed Stress Proofing expressed a wish for spiritual content.

We allowed clergy of all physical health states to participate. United Methodist clergy have previously been documented having above-average rates of chronic diseases, including hypertension, diabetes, arthritis, angina, and asthma (1). An important question is whether participants at risk of chronic disease find a stress management intervention to be feasible. In the current study, all interventions appeared feasible for clergy. Regular practice of the Daily Examen appeared especially feasible, with $80.0 \%$ practicing it on at least half of the days across 12 weeks. MBSR had the lowest daily practice of the four interventions, with $42.9 \%$ practicing it at least half of the days, which is nevertheless a remarkable behavior change for many participants. MBSR practice is likely to yield good outcomes; of the four interventions tested, it has the most robust evidence base with prior outcome studies reporting reduced symptoms of anxiety $(54,55)$, reduced symptoms of depression (56), decreased stress $(57)$, and improvement in sleep quality (58), and being effective among participants with high anxiety and poor sleep quality at baseline (59). We do not yet have a good understanding about the dose (i.e., frequency and number of minutes engaged in practice) needed to experience improvement in stress. In the current study, the number of minutes practiced (22.6) was lower than what MBSR outcome studies have tested. In one meta-analysis, the range of minutes practiced was 60-120 minutes (60). However, fewer minutes of daily practice may be beneficial. For example, Smith, Metzker (54) found decreased perceived stress, decreased anxiety, increased awareness, and increased acceptance with 15-25 minutes of daily practice.

A study objective was to identify changes to improve the interventions before proceeding to an adequately powered trial. We recommend offering an overnight stay to allow for travel time and enough calming space to practice stress management skills. For Stress Proofing, we recommend that clergy learn the skills without engaging in physical contact with one another, and incorporating reasonable spiritual concepts into activities, such as the sacredness breath. In addition, the Stress Proofing content was broad and heavily didactic; we recommend starting the workshop with an activity, being clearer on which activities to regularly practice, and cutting back on the amount of time spent teaching the physiology of stress. For Centering Prayer, some participants found it hard to sit for 20 minutes without distraction in a group setting, while others enjoyed practicing in a group; perhaps expectations could be set in advance. For the Examen, reports of the two post-workshop sessions using a web platform at 2 and 4 weeks later were highly positive; we recommend considering this structure across interventions. 
We collected data on practice adherence using text messages. Although we were initially concerned that a daily text message would be perceived as annoying, participants nearly universally indicated that they welcomed the daily message as a reminder and accountability structure, such that even programs not interested in evaluation should consider including text messages. We recommend sending the message at noon and again at $4 \mathrm{pm}$ for non-responders. We recommend personalizing the text messages with the participant's name, and varying an intro message (e.g. "Peace be with you!" every few weeks.)

We collected outcome data on a small sample of participants in this pilot trial to determine the feasibility of trial procedures. We found that the 3-week survey assessment did not contribute much unique information, and that text messages were best sent daily, as opposed to every two days. We also used the outcome data to assess the likelihood of change in symptoms for each intervention, with particular interest in the spiritual practices because relatively few studies of spiritual practice interventions for stress reduction exist. For the Examen, we found promising changes in stress and anxiety symptoms and stress reactivity, but neutral to unfavorable changes for HRV. For Centering Prayer, we found promising change patterns for HRV and stress reactivity, but increased anxiety symptoms. In contrast, another study of Centering Prayer found decreased anxiety symptoms using a different measure for participants who practiced 20 minutes six times a week. Stress Proofing showed statistically significant improvements in stress reactivity and symptoms, which is consistent with other stress inoculation training intervention studies, for example among pregnant women who report reductions in perceived stress (61). However, Stress Proofing showed deteriorations in stress response based on the HRV measures. For future tests of Stress Proofing, we recommend increased focus on and motivation for the breathing and physical practices that can be incorporated multiple times per day. For MBSR, change patterns were consistently positive. As a point of reference, the decrease in anxiety symptoms was small (-2.0 points), but akin to other studies using the same anxiety measure as an outcome for MBSR interventions (3.4 points (54); 1.9 points (62)).

We evaluated the likelihood that interventions would produce change in symptoms of stress and stress reactivity. Interventions were considered promising and moved to full trial if the point estimate of effect was close to recommendations for minimum practically significant effects (i.e. mean difference $\geq 0.41$; 53). Adopting these criteria, MBSR, Stress Proofing, and Examen were considered interventions with particular promise to improve stress management of clergy and proceeded to Phase-III efficacy testing in the ongoing Selah trial. The stress management interventions we evaluated produced less reliable change in long-term HRV parameters. RMSSD is an indirect indicator of the strength of the parasympathetic nervous system on heart rate and correlates well with high frequency HRV (63). We chose to include RMSSD given that it may serve as a proximal indicator for integration of brain mechanisms that guide flexible control over behavior with peripheral physiology and may provide an important window into understanding stress and health (64). Moreover, long-term measures of RMSSD have been associated with markers of stress at work among adults between 35 and 44 years of age (65). It has been recognized that perceived and objective measures of stress assess different aspects of the psychobiological sequelae that is stress, with multi-method assessments being favored (66). We will use 
multi-method assessments, including RMSSD, in the trial, but the sample size was not large enough in this pilot study to use RMSSD measures to inform which interventions to proceed to trial.

This study has several limitations, most notably the small sample size of the control and intervention groups. The control participants experienced some changes in outcomes despite not receiving an intervention, which may be attributable to expectancy effects, or carry-over effects between clergy enrolled in intervention groups. Timing of measurement of the control condition differed than that of the experimental condition with Time 3 assessment occurring at 8 weeks opposed to 12 weeks. This was a pragmatic decision that may impact the results observed. We recruited a convenience sample of clergy; our sample may lack the full diversity of clergy experiences. Findings are most generalizable to United Methodist clergy but may be relevant to clergy of other Christian denominations. We did not randomly assign participants to intervention arms because we believe that participant preference is important to sustain daily stress reduction practices. This introduces selection bias into intervention arms and conflates intervention effects with expectancy effects. As such, results must be interpreted in comparison to the control group or within intervention arm rather than between arms. Study strengths include collecting a variety of kinds of acceptability and feasibility data, collecting survey and physiological data, collecting daily participation data for 12 weeks, and including a control group.

In conclusion, the current study reports on Phase II preliminary testing of four potential stress reduction interventions, including two under-studied spiritual practices that may align with the values and thus preferences of Christian clergy and individuals. All four interventions were acceptable and feasible for clergy, and have the potential of appealing to busy professionals who are called to their work more broadly. The preliminary testing reported here is critical to inform trial conduct, enhance intervention redesign, and improve resource expenditure by ensuring that only well-informed interventions proceed to Phase III efficacy trials, including the Selah Phase III trial.

\section{Declarations}

\section{Ethics approval and consent to participate}

All study procedures were approved by the Duke University Campus Institutional Review Board (protocol \#2019-0238).

\section{Consent for publication}

Not applicable

\section{Availability of data and materials}

The datasets generated during the current study are not publicly available, but de-identified data will be made available on reasonable request where such requests are compliant with receipt of ethical approval from the sending and receiving hosts' institutional ethics review boards. 


\section{Competing interests}

The authors declare that they have no competing interests.

\section{Funding}

This study was funded by a grant (ORC-2096-SP) from the Rural Church Area of The Duke Endowment. The funding body did not design the study or have any role in the data collection, analysis, or interpretation or writing of the manuscript.

\section{Authors' contributions}

RJP secured funding, chose the interventions, planned the study, helped shape the content of the Daily Examen and Stress Proofing interventions, and wrote portions of the manuscript. DE secured funding, planned the study, determined the heart rate variability (HRV) data collection and analysis plan, analyzed the HRV data, and wrote portions of the manuscript. LT contributed to the study design, enacted study procedures, assisted with intervention implementation, and wrote portions of the manuscript. JY conducted survey analyses and helped write the analysis section. JR provided guidance on HRV data collection and analysis and wrote portions of the manuscript. JC collected survey and HRV data and wrote portions of the manuscript. BS oversaw text message data collection and analysis and edited the manuscript. SL enacted study procedures and wrote portions of the manuscript.

\section{Acknowledgements}

We thank the clergy participants for their travel time, patience, and wearing of EKG devices. We thank the intervention instructors, including Katie Crowe, Glenn Murphy, Mark Shaw, Mark Wethington, Julie Kosey, and Riitta Whaley. For research, implementation, and recruitment support, we thank Ernesto Ortiz, Claire Cusick, XXX Digital Sciences, the XXX Office of Clinical Research. For assistance with collecting HRV data, we thank Nneka Molokwu, Kelly Keefe, Brian Engelhardt, Essence Ingram-May and Ella Zalon.

\section{References}

1. Proeschold-Bell RJ, LeGrand SH. High rates of obesity and chronic disease among United Methodist clergy. Obesity. 2010;18(9):1867-70.

2. Lazarus RS, Folkman S. Stress, Appraisal and Coping. New York: Springer; 1984.

3. McEwen BS, Gianaros PJ. Stress- and allostasis-induced brain plasticity. Annu Rev Med. 2011;62:431-45.

4. Bergmann N, Gyntelberg F, Faber J. The appraisal of chronic stress and the development of the metabolic syndrome: a systematic review of prospective cohort studies. Endocrine Connections. 2014;3(2):R55-80.

5. Kivimaki M, Kawachi I. Work Stress as a Risk Factor for Cardiovascular Disease. Curr Cardiol Rep. 2015;17(9):630. 
6. Everyday Health. The United States of Stress 20192019 [Available from: https://www.everydayhealth.com/wellness/united-states-of-stress/.

7. Weaver AJ, Flannelly KJ, Larson DB, Stapleton CL, Koenig HG. Mental health issues among clergy and other religious professionals: a review of research. Journal of Pastoral Care \& Counseling. 2002;56(4):393-403.

8. Baruth M, Wilcox S, Evans R. The health and health behaviors of a sample of African American pastors. J Health Care Poor Underserved. 2014;25(1):229-41.

9. Halaas GW. Ministerial health and wellness: 2002 Evangelical Lutheran Church in America. Chicago, IL Evangelical Lutheran Church in America; 2002.

10. Knox S, Virginia SG, Lombardo J. Depression and anxiety in Roman Catholic secular clergy. Pastoral Psychol. 2002;50:345-58.

11. Lau B. Mental health among Norwegian priests: associations with effort-reward imbalance and overcommitment. Int Arch Occup Environ Health. 2018;91(1):81-9.

12. Proeschold-Bell RJ, Miles A, Toth M, Adams C, Smith BW, Toole D. Using effort-reward imbalance theory to understand high rates of depression and anxiety among clergy. J Prim Prev. 2013;34(6):439-53.

13. Van der Doef M, \& Maes, S. The job demand-control (-support) model and psychological well-being: a review of 20 years of empirical research. Work Stress. 1999;13(2):87-114.

14. DeShon RP. Clergy effectiveness: National survey results summary. General Board of Higher Education \& Ministry: The United Methodist Church; 2012.

15. Kuhne GW, Donaldson JF. Balancing Ministry and Management - an Exploratory-Study of Pastoral Work Activities. Review of Religious Research. 1995;37(2):147-63.

16. Carroll JW. God's potters: Pastoral leadership and the shaping of congregations. Grand Rapids, Ml: William B. Eerdmans Pub.; 2006. xvi, 296 p. p.

17. Morris ML, Blanton P. Predictors of family functioning among clergy and spouses: Influences of social context and perceptions of work-related stressors. Journal of Child \& Family Studies. 1998;7(1):27-41.

18. Proeschold-Bell RJ, \& Byassee, J. Faithful and fractured: Responding to the clergy health crisis. Grand Rapids, Ml: Grand Rapids; 2018.

19. Stewart-Sicking JA, editor Subjective well-being among Episcopal clergy. Annual Meeting of the Society for the Scientific Study of Religion and Religious Research Association; 2009; Denver, Colorado.

20. Smith TW. Job satisfaction in the United States: NORC/University of Chicago; 2007 [cited 2007 April 17]. Available from: http://www-news.uchicago.edu/releases/07/pdf/070417.jobs.pdf.

21. Johnson MJ, Jiang L. Reaping the benefits of meaningful work: The mediating versus moderating role of work engagement. Stress \& Health. 2017;33(3):288-97. 
22. Adams C, Bloom M. Flourishing in Ministry: Wellbeing at Work in Helping Professions. Journal of Psychology and Christianity. 2017;36(3):254-9.

23. Varvogli L, \& Darvivi, C.. Stress management techniques: Evidence-based procedures that reduce stress and promote health. Health Science Journal. 2011;5(2):74-89.

24. Rao NP, Varambally S, Gangadhar BN. Yoga school of thought and psychiatry: Therapeutic potential. Indian J Psychiatry. 2013;55(Suppl 2):S145-9.

25. Walton KG, Schneider, R. H., Nidich, S. I., Salerno, J. W., Nordstrom, C. K., \& Bairey Merz, C. N.. Psychosocial stress and cardiovascular disease part 2: Effectiveness of the transcendental meditation program in treatment and prevention. Behav Med. 2002;28(3):106-23.

26. Spring B. Evidence-based practice in clinical psychology: what it is, why it matters; what you need to know. J Clin Psychol. 2007;63(7):611-31.

27. Frögéli E, Rudman A, Ljótsson B, Gustavsson P. Preventing stress-related ill health among newly registered nurses by supporting engagement in proactive behaviors: development and feasibility testing of a behavior change intervention. Pilot and Feasbility Studies. 2018;4(28):1-14.

28. Braun SS, Roeser RW, Mashburn AJ. Results from a pre-post, uncontrolled pilot study of a mindfulness-based program for early elementary school teachers. Pilot and Feasbility Studies. 2020;6(178):1-12.

29. Czajkowski SM, Powell LH, Adler N, Naar-King S, Reynolds KD, Hunter CM, et al. From ideas to efficacy: The ORBIT model for developing behavioral treatments for chronic diseases. Health Psychol. 2015;34(10):971-82.

30. Shapiro SL, Astin JA, Bishop SR, Cordova M. Mindfulness-based stress reduction for health care professionals: Results from a randomized trial. International Journal of Stress Management. 2005;12(2):164-76.

31. Krick A, Felfe J, Klug K. Building resilience: Trajectories of heart rate variability during a mindfulnessbased intervention and the role of individual and social characteristics. International Journal of Stress Management. 2021;38(3):220-31.

32. Kabat-Zinn J. Full catastrophe living: Using the wisdom of your body and mind to face stress, pain, and illness. New York, NY: Bantam Dell; 2013.

33. Grossman P, Niemann, L., Schmidt, S., \& Walach, H.. Mindfulness-based stress reduction and health benefits: A meta-analysis. Focus on Alternative and Complementary Therapies. 2010;8(4):35-43.

34. Teasdale JD, Segal, Z. V., \& Williams, J. M. G. How does cognitive therapy prevent depressive relapse and why should attentional control (mindfulness) training help? Behavioural Research and Therapy. 1995;33:25-39.

35. Meichenbaum D. Stress inoculation training: A preventative and treatment approach. New York, NY: Guilford Press; 2007. 497-518 p.

36. Meichenbaum D, \& Cameron, R.. Stress inoculation training: Toward a general paradigm for training coping skills. Stress reduction and prevention. 1983:115-54. 
37. Thibodeaux M. Reimagining the Ignatian examen: Fresh ways to pray from your day. Chicago, IL: Loyola Press; 2015.

38. Case AD, Keyes CLM, Huffman KF, Sittser K, Wallace A, Khatiwoda P, et al. Attitudes and behaviors that differentiate clergy with positive mental health from those with burnout. Journal of Prevention \& Intervention in the Community. 2020;48(1):94-112.

39. Liza VD, C. Stress management techniques: evidence-based procedures that reduce stress and promote health. Health Science Journal. 2011;5(2):74-89.

40. Hayter J, Taylor, L, and Smith, C. Centering Prayer and Closeness to God. International Journal of Spiritual Direction. 2019;25(1):43-51.

41. Johnston E. The enlightened self: Identity and aspiration in two communities of practice. Religions. 2016;7(7).

42. Carlson LE, Thomas BC. Development of the Calgary Symptoms of Stress Inventory (C-SOSI). Int J Behav Med. 2007;14(4):249-56.

43. Schlotz W, Yim IS, Zoccola PM, Jansen L, Schulz P. The Perceived Stress Reactivity Scale: measurement invariance, stability, and validity in three countries. Psychol Assess. 2011;23(1):80-94.

44. Zigmond AS, Snaith RP. The hospital anxiety and depression scale. Acta Psychiatr Scand. 1983;67(6):361-70.

45. Bjelland I, Dahl AA, Haug TT, Neckelmann D. The validity of the Hospital Anxiety and Depression Scale. An updated literature review. J Psychosom Res. 2002;52(2):69-77.

46. Frenk SM, Mustillo SA, Hooten EG, Meador KG. The Clergy Occupational Distress Index (CODI): background and findings from two samples of clergy. Journal of Religion and Health. 2013;52(2):397-407.

47. Berntson GG, Quigley KS, Jang JF, Boysen ST. An approach to artifact identification: application to heart period data. Psychophysiology. 1990;27(5):586-98.

48. Penttila J, Helminen A, Jartti T, Kuusela T, Huikuri HV, Tulppo MP, et al. Time domain, geometrical and frequency domain analysis of cardiac vagal outflow: effects of various respiratory patterns. Clin Physiol. 2001;21(3):365-76.

49. Refinetti R, Cornélissen G, Halberg F. Procedures for numerical analysis of circadian rhythms. Biol Rhythm Res. 2007;38(4):275-325.

50. R Development Core Team. R: A language and environment for statistical computing. Vienna, Austria: R Foundation for Statistical Computing; 2011.

51. Hsieh HS, SE. Three approaches to qualitative content analysis. Qual Health Res. 2005;15(9):127788.

52. StataCorp. Stata Statistical Software: Release 16.1. College Station, TX: StataCorp LLC; 2019.

53. Ferguson CJ. An effect size primer: A guide for clinicians and researchers. Professional Psychology: Research and Practice. 2009;40(5):532-8. 
54. Smith B, Metzker K, Waite R, Gerrity P. Short-form mindfulness-based stress reduction reduces anxiety and improves health-related quality of life in an inner-city population. Holist Nurs Pract. 2015;29(2):70-7.

55. Zhang MF, Wen YS, Liu WY, Peng LF, Wu XD, Liu QW. Effectiveness of Mindfulness-based Therapy for Reducing Anxiety and Depression in Patients With Cancer: A Meta-analysis. Medicine (Baltimore). 2015;94(45):e0897-0.

56. Goldin PR, Gross JJ. Effects of mindfulness-based stress reduction (MBSR) on emotion regulation in social anxiety disorder. Emotion. 2010;10(1):83-91.

57. Burton A, Burgess, C., Dean, S., Koutsopoulou, G. Z., \& Hugh-Jones, S.. How effective are mindfulness-based interventions for reducing stress among healthcare professionals? A systematic review and meta-analysis. Stress \& Health. 2017;33:3-17.

58. Karaca A, \& Şişman, N. Y.. Effects of a stress management training program with mindfulness-based stress reduction. J Nurs Educ. 2019;58(5):273-80.

59. Brown MM, Arigo D, Wolever RQ, Smoski MJ, Hall MH, Brantley JG, et al. Do gender, anxiety, or sleep quality predict mindfulness-based stress reduction outcomes? J Health Psychol. 2020.

60. Veehof MM, Trompetter HR, Bohlmeijer ET, Schreurs KM. Acceptance- and mindfulness-based interventions for the treatment of chronic pain: a meta-analytic review. Cogn Behav Ther. 2016;45(1):5-31.

61. Khorsandi M, Vakilian K, Salehi B, Goudarzi MT, Abdi M. The effects of stress inoculation training on perceived stress in pregnant women. J Health Psychol. 2016;21(12):2977-82.

62. Dvorakova K, Kishida M, Li J, Elavsky S, Broderick PC, Agrusti MR, et al. Promoting healthy transition to college through mindfulness training with first-year college students: Pilot randomized controlled trial. J Am Coll Health. 2017;65(4):259-67.

63. Malik M. Heart rate variability: standards of measurement, physiological interpretation, and clinical use. Circulation. 1996;93(5):1043-65.

64. Thayer JF, Ahs F, Fredrikson M, Sollers JJ, 3rd, Wager TD. A meta-analysis of heart rate variability and neuroimaging studies: implications for heart rate variability as a marker of stress and health. Neurosci Biobehav Rev. 2012;36(2):747-56.

65. Loerbroks A, Schilling O, Haxsen V, Jarczok MN, Thayer JF, Fischer JE. The fruits of ones labor: Effort-reward imbalance but not job strain is related to heart rate variability across the day in 35-44year-old workers. J Psychosom Res. 2010;69(2):151-9.

66. Weckesser LJ, Dietz F, Schmidt K, Grass J, Kirschbaum C, Miller R. The psychometric properties and temporal dynamics of subjective stress, retrospectively assessed by different informants and questionnaires, and hair cortisol concentrations. Sci Rep. 2019;9(1):1098.

\section{Figures}




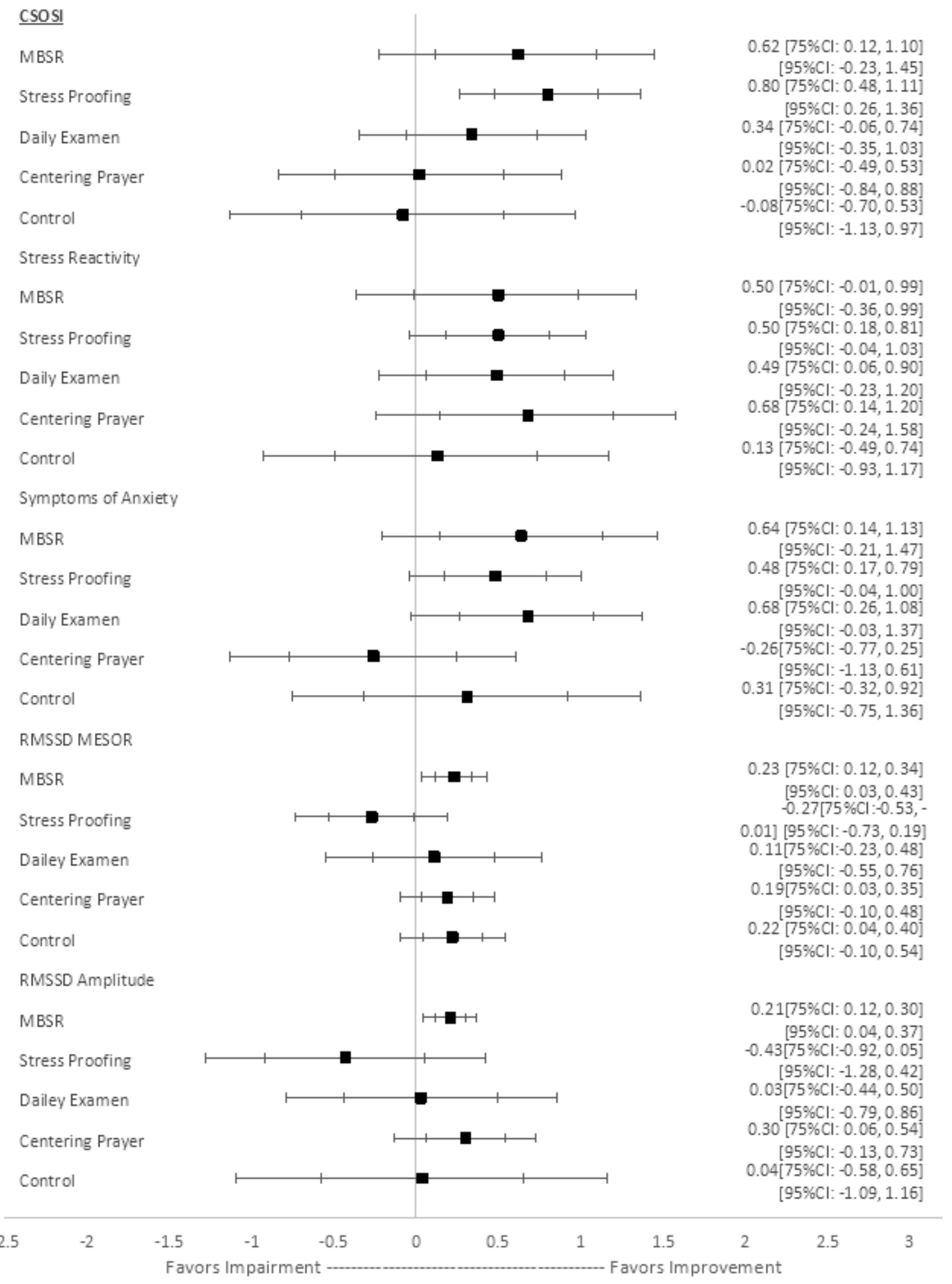

\section{Figure 1}

Within-group estimates and confidence intervals for five outcomes by treatment arm 


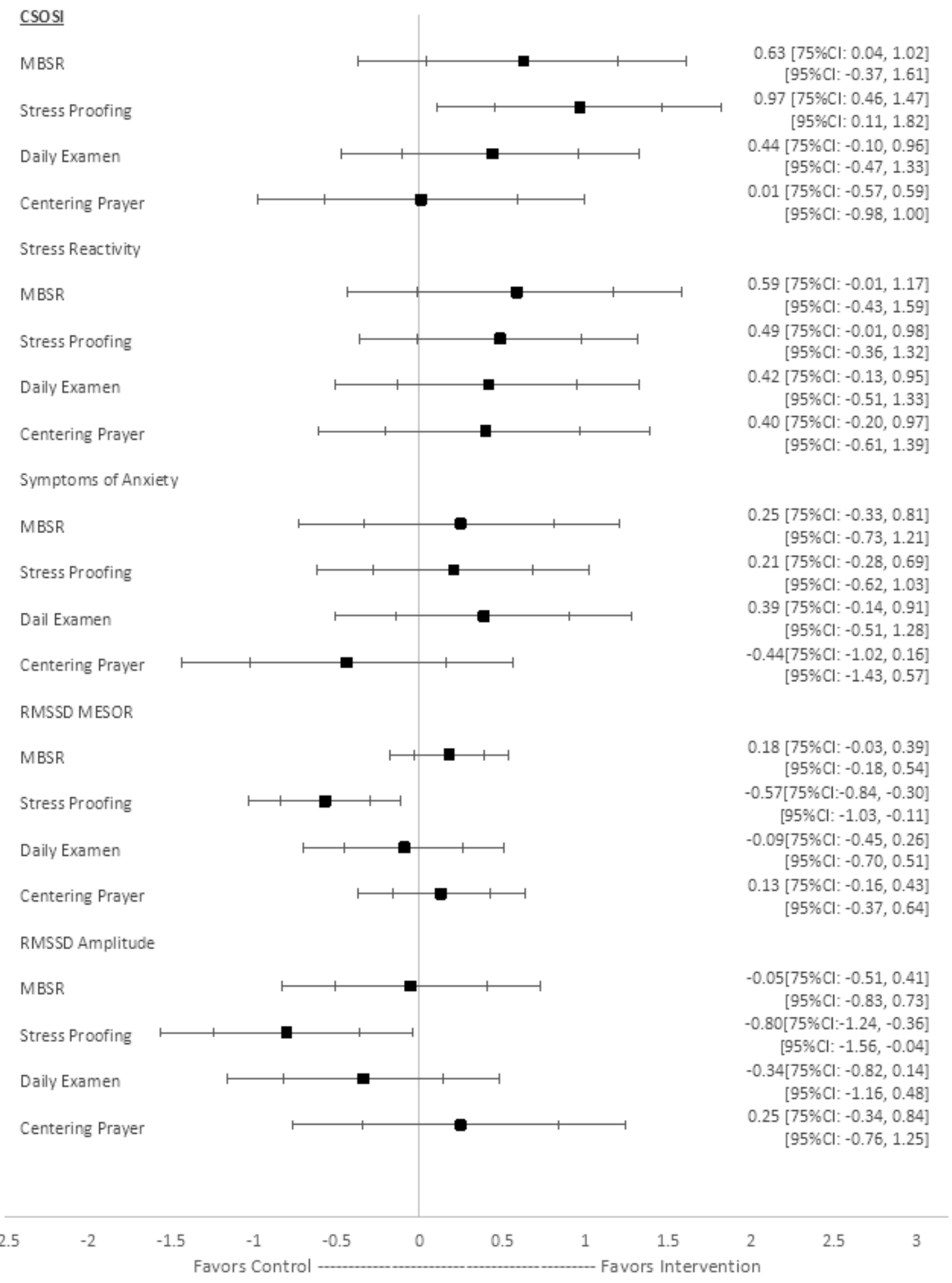

\section{Figure 2}

Between-group estimates and confidence intervals for five outcomes by treatment arm

\section{Supplementary Files}

This is a list of supplementary files associated with this preprint. Click to download. 
- CONSORTextensionChecklistSelah.doc 